\section{Contents}

The Interaction of Highly Charged lons with Surfaces

by $R$. Morgenstern, J. Das

Marrying Cluster Physics and Nuclear Physics -

A Prolific Union

by $\mathrm{S}$. Bjørnholm

\section{Editorial Board}

P. Bochsler, Bern University

S. Ciliberto, ENS, Lyon

All Eyes on Europe

7

A.-J. Dianoux, ILL, Grenoble

Editor: P.G. Boswell

Exec. Sec.: G. Thomas

\section{Editorial and Advertising}

LHC: Opening-Up Urged

18

B. Pontecorvo

17

From the President

15

The Treasurer Reports

16

EPS on World-Wide Web

6

HEWLETT-PACKARD EUROPHYSICS PRIZE: 1994 Award

EPS Secretariat, P. O.Box 69

$\mathrm{CH}-1213$ Petit-Lancy 2, Geneva

Telephone: $\quad+41$ (22) 7931130

Telefax: $\quad+41(22) 7931317$

E-mail: epnews@cernvm.cern.ch

Advertising is charged according to space, on a sliding scale ranging from SFR 2700.- for a full page to SFR 700.- for a one-sixth page. Rates for four-colour and cover advertising, and series insertions, on application. Special rates for Associate Members of EPS; $25 \%$ reduction for announcements of situations vacant.
T. Jarlborg, Geneva University

J. Schacher, Bern University

M. Siegrist, EPFL, Lausanne

President: N. Kroó KFKI, Budapest

Deadline for advertising orders: first week of month of publication.

Subscriptions \& EPS Fees:

Société de Banque Suisse,

Geneva; Acc. No. 164.899

Swiss Post Office Acc.: CCP

Geneva 12-19107-4

German Post Office Acc.: Postbank

Karlsruhe 1801-30-754

Eurocheque to EPS, Geneva

EPS Budapest Secretariat

Nádor u. 7, H-1051 Budapest

Telephone: $\quad+36(1) 1173510$

Telefax: $\quad+36(1) 1176817$

\section{PLASMA PHYSICS DIVISION: Call for Nominations}

\section{- Europhysics Notes}

19

High-Tc; VIRGO; ELETTRA:

Hubble Space Telescope;

French national debate; Neutron sources

\begin{abstract}
Cover illustration
Different phases during the collision of a multiply charged ion with a solid surface: electrons are captured in front of the surface into excited states, thus forming a "hollow atom" which subsequently decays via Auger cascades. Outer electrons are peeled off during penetration into the solid, and a Coulomb explosion of the volume depleted in electrons may occur. See R. Morgenstern and J. Das, page 3. (Illustration courtesy of H. Limburg.)
\end{abstract}

\title{
News and Science
}

Members and subscribers receive their News flat and under plastic this month, partly to move with the times but also to reduce costs as modern binding machines plastic wrap on line. One can now have an abbreviated contents list on the cover which is seen through the plastic, and this entailed some rearrangement. The Editorial Board did not want to move to a full-page colour cover as it aims to use the cover in an informative way by reproducing a relevant and illustrative figure. Another change is that Fred James, owing to increasing commitments elsewhere, steps down as Chairman. He has provided invaluable advice and support for the eight years he served on the Board.

The policy of integrating news and science will continue since it is felt that working physicists and interested observers hope to see Society activities forming part of the everyday affairs of physics. Moreover, by relating news to science one can develop themes that interest advertisers (an important point for a fairly specialized publication with a modest, though high quality, circulation). The American Physical Society has meanwhile changed its APS News to a tabloid newspaper format after two years, partly to reduce costs, but also to provide a more appropriate publication. Harry Lustig, the Treasurer and until 1 April the Acting Executive Secretary when Judy Franz, presently Professor of Physics at the University of Alabama, takes over, writes that members wanted a crisper news section and liked Letters to the Editor and meeting announcements (and occasionally even editorials). But there will continue to be very little coverage of physics in spite of some members writing in to say that the APS and it organs should address physics, not public affairs. Burton
Richter, the APS President, replies that members wanted the society to become more involved in policy and specific social issues as they affect physics; APS News by implication reflects this thinking. Whether it can fulfill its mission with little reference to physics, and the way and the how it is done, remains to be seen.

The backdrop to this is what the European Communities' Esprit programme calls the "beginning of the transition to a new information infrastructure for society", where the challenge is to enable people to make sense of the huge amounts of information that are becoming available. Europhysics News can envisage going electronic as the Society is now "on the web" (p. 6) as they say thanks to Eddy Lingeman and colleagues at NIKHEF. Easily implemented is the type of service announced by APS where members will be able to receive APS News items by selecting from a menu (a slightly less sophisticated service, technologically speaking, is to be launched this spring by IOPP under the banner Physics World Electronic News).

This Editor is probably inexperienced enough to believe that printed versions will always have their place. Complementarity is the keyword, as demonstrated by letters journals that have begun to make classification numbering schemes available to authors via electronic networks. But one should not forget the opportunities offered by hypermedia, journal servers and even virtual reality for which there now exists reasonably affordable (at least for some) software able to run on a PC. Virtual reality aims to immerse one in a 3-d image with sound, movement, vibration, etc., indeed the whole works. So we may be able to imagine for ourselves what it might be like to lie on a Sardinian beach, cold beer in hand, sensing some distant earthquake. While the effort to set this up seems disproportionate in this case, the opportunities must not be denied, and here it seems physicists are moving slowly. Chemists showed at recent conference in London how "feeling" where atoms can be added to complex molecules helps decide where the real atoms should go. Physicists, by contrast, were not "sitting" in turbulent flow fields or plasma discharges and "sensing" what is happening. Adding "reality" may add understanding and a source of insight - like those old, flat, outputs of simulations. So this Editor faces a world where one day a review of ions hitting surfaces (p. 3) comes direct to your screen courtesy of Europhysics News complete with a virtual reality demonstration.

Returning closer to home, as discussed by the President on page 15, Council in Cracow in March will be asked to approve a new membership category whereby national society members become EPS members (a revised Constitution and $B y$-Laws was mailed to members last November for comment). The Editor was asked to formulate a working arrangement for publishing EPS pages in Physics World and Physikalische Blätter in order to be able to inform members in the loP and the German Physical Society, who will not receive News when the new category is introduced. It seemed that distilling out of News items for publication in other bulletins was in harmony with the basic philosophy of integrating science and news; considerable goodwill ensured agreement that this approach would provide a reasonable basis for setting the ball rolling.

P.G. Boswell 